\title{
Entrevista narrativa com pessoas em situação de rua com transtornos mentais: relato de experiência
}

\author{
Narrative interview with homeless persons with mental illness: experience report \\ Entrevista narrativa con personas en la situación de la calle con trastornos mentales: informe de \\ experiencia
}

Letícia Passos Pereira ${ }^{1}$ (1)

Christine Wetzel ${ }^{1}$ (B)

Fabiane Machado Pavani ${ }^{1}$ (D)

Agnes Olschowsky ${ }^{1}$ (1)

Bárbara Maix Moraes ${ }^{2}$ (b)

Evelyn Klein ${ }^{3}$ (C)

1. Universidade Federal do Rio Grande do Sul,

Programa de Pós-Graduação em Enfermagem.

Porto Alegre, RS, Brasil.

2. Pontifícia Universidade Católica do Rio Grande do Sul, Programa de Residência Multiprofissional em Urgência. Porto Alegre, RS, Brasil.

3. Universidade Federal do Rio Grande do Sul, Escola de Enfermagem. Porto Alegre, RS, Brasil.

\begin{abstract}
Resumo
Objetivo: relatar a experiência do uso da entrevista narrativa com pessoas em situação de rua com transtornos mentais. Método: relato de experiência realizada em uma capital do Sul do Brasil. A coleta de dados ocorreu de julho a outubro de 2019. Resultados: a aplicação da entrevista narrativa desenvolveu-se em duas etapas: aproximação com o campo e seleção dos participantes; e construção da narrativa. A primeira envolveu uma inserção em um Consultório na Rua e possibilitou a identificação e o desenvolvimento de vínculo com os usuários. A segunda ocorreu com o desenvolvimento da entrevista narrativa e envolveu os seguintes passos: contato e negociação, história principal e fase de questionamentos. Conclusão: a entrevista narrativa se apresenta como ferramenta metodológica com potencial para a construção de itinerários terapêuticos de pessoas em situação de rua com transtornos mentais, contextualizando suas opções na busca pelo seu cuidado na perspectiva de suas histórias de vida. Implicação para a prática: a entrevista narrativa possibilita fazer-se ouvir em histórias frequentemente negligenciadas. Por ter como foco central a construção de sentidos por parte de quem vivencia determinada realidade, permitiu a reconstrução desses, possibilitando novos olhares e insights em relação à própria experiência de quem relatava.
\end{abstract}

Palavras-chaves: Saúde Mental; Narração; Pessoas em Situação de Rua; Pesquisa Qualitativa

\section{Abstract}

Objective: report the experience of using the narrative interview with homeless persons who suffer from mental disorders. Method: experience report held in a capital city in the South of Brazil. The data collection took place from July to October 2019. Results: the application of the narrative interview was developed in two stages: approach to the field and selection of participants; and construction of the narrative. The first involved an insertion in a Street Office and made it possible to identify and develop a link with the users. The second occurred with the development of the narrative interview and involved the following steps: contact and negotiation, main story and questioning phase. Conclusion: the narrative interview presents itself as a methodological tool with potential for the construction of therapeutic itineraries for homeless persons with mental disorders, contextualizing their options in the search for their care from the perspective of their life stories. Implication for practice: narrative interviewing makes it possible to make oneself heard in often neglected stories. By having as a central focus the construction of senses by those who experience a certain reality, it allowed the reconstruction of these, allowing new looks and insights in relation to the very experience of those who reported.

Keywords: Mental Health; Narration; Homeless Persons; Qualitative Research.

\section{Resumen}

Objetivo: relatar la experiencia de utilizar entrevistas narrativas con personas en situación callejera con trastornos mentales. Método: informe de experiencia realizado en una capital del Sur de Brasil. La recolección de datos tuvo lugar de julio a octubre de 2019. Resultados: La aplicación de la entrevista narrativa se desarrolló en dos etapas: aproximación al campo y selección de participantes; y construcción de la narrativa. La primera implicó una inserción en un Consultório na Rua y permitió identificar y desarrollar vínculos con los usuarios. La segunda ocurrió con el desarrollo de la entrevista narrativa y contó con los siguientes pasos: contacto y negociación, historia principal y fase de cuestionamientos. Conclusión: la entrevista narrativa se presenta como una poderosa herramienta metodológica para la construcción de itinerarios terapéuticos para personas en situación callejera con trastornos mentales, contextualizando sus opciones en la búsqueda de su cuidado desde la perspectiva de sus historias de vida. Implicación para la práctica: la entrevista narrativa permite hacerse oír en historias que a menudo se pasan por alto. Debido a que tiene como foco central la construcción de significados por parte de quienes experimentan una determinada realidad, permitió la reconstrucción de estos, posibilitando nuevas miradas y percepciones en relación a la propia experiencia de quien informa.

Palabras clave: Salud Mental; Narración; Personas sin Hogar; Investigación Cualitativa
Autor Correspondente Letícia Passos Pereira leti_passos@msn.com

Recebido em 04/02/2020.

Aprovado em 30/11/2020.

DOI:https://doi.org/10.1590/2177-9465-EAN-2020-0017 


\section{INTRODUÇÃO}

A população de rua faz parte, de maneira crescente, do cenário das grandes cidades, e o imaginário social a concebe como um grupo homogêneo de indivíduos imersos na pobreza, que utilizam espaços públicos para dormir, comer, fazer suas necessidades fisiológicas e usar drogas, reduzindo a percepção sobre o que esse indivíduo faz e como utiliza o espaço da rua, sobre a falta de recursos, de domicílio próprio ou regular e de higiene. ${ }^{1}$

Esses indivíduos são compreendidos como parte de um contingente que, historicamente, passou a fazer parte do cenário das cidades, e por não serem reconhecidos como cidadãos, mas como "não sujeitos", são discriminados e alvo de preconceitos e estigmas. Essa população, vítima de inúmeras formas de violência, é invisibilizada e colocada em permanente condição de vulnerabilidade ${ }^{2}$, que resulta em negligência e desassistência também em consequência da ausência de políticas públicas voltadas a essas pessoas.

Por se tratar de um grupo heterogêneo, há uma parte dele cuja invisibilidade é acentuada: as pessoas em situação de rua com transtornos mentais, que vêm sendo naturalmente excluídas do próprio grupo em situação de rua.

As questões relacionadas ao cuidado em saúde mental direcionado à população de rua, nos serviços de saúde, nas políticas públicas e na literatura, frequentemente têm como ênfase o uso de drogas, de modo que os transtornos mentais - esquizofrenia, transtorno afetivo bipolar, depressão - ficam à margem e implicam o desafio de gerar um cuidado psicossocial para esse grupo específico.

A Reforma Psiquiátrica Brasileira (RBP), ao propor transformar o modo de atenção asilar em saúde mental em um cuidado em rede psicossocial, amplia a discussão sobre o espaço da loucura. No entanto, percebe-se que a cidade ainda permanece de costas para o diferente, para tudo o que quebre sua ilusão de homogeneidade, segregando, assim, os loucos - ainda mais quando são os "loucos em situação de rua".

Nessa direção, ainda existem lacunas epistemológicas e práticas em relação às especificidades no cuidado em saúde mental prestado à população de rua com transtornos mentais, a qual requer cuidados particularizados, que ofereçam flexibilidade e sejam centrados na pessoa. ${ }^{3}$ Assim, entende-se que os avanços na mudança paradigmática de atenção em saúde mental, a partir da RPB, apresentam entraves relacionados ao cuidado a grupos específicos, entre os quais as pessoas em situação de rua com transtornos mentais, que permanecem desassistidas por serviços de saúde em geral e pela Rede de Atenção Psicossocial. Portanto, ressalta-se a importância de realizar pesquisas, na perspectiva psicossocial, que permitam pensar sobre as formas que o cuidado em saúde mental vem assumindo e sobre como a rede de saúde mental responde ao cuidado voltado a grupos específicos. Ademais, urge compreender como são construídas as relações de cuidado com esses grupos, o que exige dar voz às subjetividades negligenciadas, oprimidas ou desconhecidas. ${ }^{4}$
Em razão disso, tem-se, na perspectiva dos Itinerários Terapêuticos (ITs), uma estratégia de pesquisa que possibilita apreender os movimentos, as dinâmicas e as relações que as pessoas constroem no seu cotidiano na busca pelo seu cuidado. Os ITs apresentam-se como um conjunto de interações práticas que os grupos sociais tecem para abrir campos de possibilidades para o cuidado à saúde. Nessa perspectiva, na presente pesquisa não só se considera que os atores apresentam diferentes cursos de ação, vacilações, dúvidas, entradas e saídas em diversas modalidades terapêuticas, mas, principalmente, compreende-se que o cuidado não se restringe à busca de tratamento. Visase, sim, primordialmente, ao desenvolvimento de arranjos e estratégias e ao estabelecimento de redes sociais constituídas no processo de lidar com a "doença". ${ }^{5}$

Assim, as escolhas realizadas, de acordo com as necessidades (e possibilidades) individuais, são apoiadas pelas redes sociais das quais as pessoas fazem parte, e que podem ser analisadas na perspectiva dos ITs, evidenciando como essas redes são estabelecidas e construídas, quais seus sentidos e significados.

A abordagem dos ITs permite que o desenho de pesquisa seja constituído por técnicas metodológicas diferentes, mas complementares, as quais possibilitem a compreensão da lógica dos participantes em sua trajetória na busca por cuidado. Justifica-se a opção pela entrevista narrativa porque se buscou captar percepções relacionadas ao transtorno mental associadas à vida nas ruas e, sobretudo, à experiência de busca por cuidado no contexto das relações e conexões estabelecidas ao longo da trajetória da vida, possibilitando a reconstrução dos ITs.

Além disso, os estudos sobre ITs, a partir da compreensão da narrativa, têm proporcionado às pessoas a inclusão de novas perspectivas no seu modo de viver e de se organizar em sociedade. De igual modo, lançam luz no que diz respeito às práticas e às estratégias utilizadas no enfrentamento de problemas cotidianos, sobretudo em relação à procura de cuidados em saúde em contextos de iniquidades sociais. ${ }^{6}$

Pode-se acrescentar que, ao se considerar que as pessoas constroem suas histórias em meio à heterogeneidade de seus contextos subjetivos, socioculturais e de acessibilidade à atenção ao adoecimento, a construção de narrativas de pessoas que vivem cercadas pela pluralidade desses elementos deve considerar a singularidade de cada uma, tanto em relação aos aspectos objetivos quanto aos subjetivos. Com base nisso, o uso de narrativas pode ser aplicado à construção de ITs, porém, isso não significa desenhar um plano esquematizado e predeterminado, mas, sim, composto por elementos que emergem das experiências pessoais. ${ }^{7}$

A partir do exposto, é preciso que se reflita criticamente sobre como as pessoas em situação de rua com transtornos mentais traçam seus caminhos na busca por cuidado. Da mesma forma, deve-se pensar sobre quais são as implicações disso na elaboração de modos de cuidar em saúde mental. ${ }^{7}$

Com base nesses pressupostos, neste artigo tem-se o objetivo de relatar a experiência do uso da entrevista narrativa com pessoas em situação de rua com transtornos mentais. 


\section{MÉTODO}

Trata-se de um relato de experiência que aborda a aplicação da entrevista narrativa junto a pessoas em situação de rua com transtornos mentais.

O contexto do estudo, no qual foram obtidas as narrativas, foi a região Central de uma capital do Sul do Brasil, em um município que apresenta a maior porcentagem de pessoas vivendo na rua. Optou-se por utilizar, como mediador do contato com os participantes, o Consultório na Rua, que conta com mais de três mil usuários em situação de rua cadastrados.

Foram realizadas oito entrevistas individuais, no período de julho a outubro de 2019, e os participantes receberam nomes fictícios de modo a não serem identificados.

Cabe ressaltar que, para a realização deste estudo, foram garantidos os preceitos ético-legais aplicados a pesquisas realizadas com seres humanos, de acordo com a Resolução n. 466/2012, do Conselho Nacional de Saúde do Ministério da Saúde, obedecendo-se às disposições presentes na Resolução n. 510/2016, que prevê especificidades nas normas aplicáveis a pesquisas em Ciências Humanas e Sociais. A pesquisa à qual este relato está atrelado foi aprovada pelo Comitê de Ética em Pesquisa da Universidade Federal do Rio Grande do Sul, sob o Parecer 3.272.312.

\section{Entrevista narrativa: aspectos teórico-conceituais}

A entrevista narrativa constrói dados textuais que reproduzem, de forma completa, o entrelaçamento dos acontecimentos e a sedimentação da experiência da história de vida do entrevistado. Assim, leva-se em conta não apenas o curso externo dos acontecimentos, mas também as reações internas, as experiências do informante com os eventos e sua elaboração interpretativa por meio de modelos de análise que conduzem a uma apresentação pormenorizada. $^{8}$

Uma das características da entrevista narrativa é a adoção de ferramentas não estruturadas, com o intuito de obter maior profundidade sobre o tema a ser pesquisado, momento em que surgem histórias de vida da pessoa entrevistada e do contexto social em que ela habita. $O$ objetivo é proporcionar mais estímulo para quem está relatando os acontecimentos da sua vida, dando maior espaço para que fale. ${ }^{9}$

Assim, as narrativas "abrem as portas" à subjetividade e a novos significados sobre situações e experiências: a pessoa que narra e fala sobre sua experiência assume um papel central no processo de cuidar, emergindo e se tornando parte ativa do processo. ${ }^{10}$ Ao considerar a população em situação de rua como informante, pode-se considerar também a vantagem de "fazer-se ouvir", pois, por não serem ouvidas, essas pessoas, frequentemente estigmatizadas e, consequentemente, excluídas de pesquisas, têm suas histórias ignoradas.

As entrevistas narrativas podem ajudar a aprender — de maneira rica e diferenciada - mais sobre os fenômenos sociais que estão na essência de histórias individuais. Considerar o contexto e os relacionamentos que influenciam a narração de histórias é importante ao se analisar dados de entrevistas narrativas e, além disso, a direção da narrativa é canalizada e determinada pelo participante, o qual escolhe as histórias que são mais significativas para ele. ${ }^{11}$

Assim, a partir da utilização de narrativas busca-se estabelecer a estrutura de um episódio, organizar a sequência dos eventos, estabelecer explicações por meio da sua interpretação, identificando os dramas e/ou conflitos sociais e os significados que dão sentido à experiência. ${ }^{12}$ No entanto, interessa menos ordená-la em uma cronologia do tipo anamnese e mais encadeá-la em um modo próprio, guiada pelo relevo dado pelas próprias pessoas às suas experiências, referidas sempre a "seu tempo e lugar". ${ }^{13}$

Nesse sentido, valorizam-se os diferentes linguajares e expressões: sonoridade da voz, tons, emoções, ritmo, intensidades, silêncios, reticências entre outros. Além disso, o relato se produz e é constituído no campo da ação, ou seja, as histórias também são contadas por meio do corpo, e a gestualidade deve ser entendida como "modo próprio de dizer". ${ }^{13}$

$\mathrm{Na}$ entrevista narrativa, o entrevistador deve usar a forma de linguagem do informante, pois esse método permite que o ponto de vista do entrevistado seja mais bem compreendido quando se usa sua linguagem de meio espontâneo. ${ }^{9}$ Assim, nessa perspectiva, tais aspectos devem ser considerados como um modo específico de vida, e não apenas como um reflexo da percepção sobre o evento.

Nesse sentido, as narrativas devem ser compreendidas pela interpretação de quem as conta, privilegiando a realidade do que é experienciado pelos informantes, referindo-se ao que é real para eles. Propõem-se representações/interpretações particulares do mundo, não estando abertas à comprovação e não podendo ser simplesmente julgadas como verdadeiras ou falsas. Além disso, pressupõe-se que as narrativas expressem a verdade de um ponto de vista, de uma situação específica no tempo e no espaço, sempre inseridas no contexto socio-histórico. ${ }^{9}$

O que se guarda na memória é seletivo, e alguns acontecimentos podem ser esquecidos, tanto intencional quanto inconscientemente. Sendo assim, o que importa é aquilo que a pessoa manteve registrado de sua história e o que é verdade para ela, e não como de fato foram os acontecimentos. $\mathrm{Na}$ narrativa, o que importa é a expressão de um ponto de vista em determinado contexto social e histórico. ${ }^{9}$

Nessa direção, as entrevistas narrativas podem ajudar os profissionais a entender melhor as experiências e os comportamentos das pessoas em comparação com outros meios quantitativos de pesquisa. Isto porque as entrevistas narrativas não se preocupam com a verdade absoluta dos fatos, mas com o significado das experiências vividas. ${ }^{10}$

Sendo a narrativa um método de captar a experiência, e sendo a experiência algo fundamental de se alcançar nas pesquisas qualitativas, nessa sistemática de entrevista tanto o pesquisador quanto o entrevistado sairão modificados do encontro. ${ }^{14}$ Assim, utilizar essa perspectiva metodológica se justifica pelo poder que tem de gerar histórias, pois é um método que permite que se vá além das respostas isoladas. ${ }^{15}$ 


\section{Entrevista narrativa: aspectos práticos}

A utilização da entrevista narrativa como técnica de coleta de dados precisa ser contextualizada à medida que demanda aproximações com um grupo específico. Para tanto, apresenta-se, em um primeiro momento, a descrição de como aconteceu essa aproximação e a seleção dos participantes e, após, a realização da entrevista propriamente dita.

\section{Aproximação com o campo e seleção dos participantes}

A pesquisa com pessoas em situação de rua requer estratégias de aproximação e sensibilidade ao contexto. Nessa direção, a pesquisa qualitativa proporciona uma profunda compreensão do ponto de vista dos participantes, tornando possível elaborar explicações adequadas para os comportamentos sociais. A partir de uma observação mais próxima, de longa duração, em determinado contexto social, torna-se possível construir um relato narrativo dos processos causais e colocar em um continuum diacrônico a coerência entre eventos e ações. ${ }^{16}$

A aproximação com o campo de pesquisa ocorreu através de um projeto de extensão no serviço de referência; o objetivo era ampliar o olhar voltado às pessoas em situação de rua com transtorno mental, buscando conhecer as especificidades das necessidades de saúde desse grupo. As atividades do projeto foram desenvolvidas ao longo de 10 meses, com quatro a cinco turnos por semana.

No período mencionado, foram identificadas pessoas em situação de rua com transtornos mentais durante o acompanhamento das atividades desenvolvidas pela equipe do serviço, abordando pessoas em situação de rua no território; buscou-se conhecer as necessidades de cuidado em saúde e os recursos disponíveis, desenvolvendo-se propostas de intervenção e de cuidado que abarcavam as pessoas acompanhadas e a rede de apoio. Com isso, foi possível conhecer os potenciais participantes da pesquisa e iniciar a aproximação fundamental para desenvolver as etapas seguintes. Assim, ao se identificar os usuários com transtornos mentais era-Ihes proposta uma conversa informal, visando conhecer um pouco mais sobre sua vida e seu acompanhamento no serviço, sem ainda mencionar a pesquisa.

Cada encontro foi uma oportunidade de reafirmar os valores que sustentam a relação participante-pesquisador, e o processo de aproximação com o campo e com os participantes permitiu a criação de vínculo e o estabelecimento de uma relação de confiança entre eles e a pesquisadora.

Inicialmente, a seleção dos possíveis participantes foi realizada a partir dos critérios de inclusão previstos (ser maior de 18 anos, estar em situação de rua há pelo menos seis meses, ser diagnosticado com algum transtorno mental e apresentar condições de compreender a pesquisa). No entanto, após a realização de duas entrevistas percebeu-se que tais critérios não foram suficientes, sendo necessária uma avaliação mais aprofundada sobre as condições de o indivíduo construir uma narrativa naquele momento. As condições para participar, nesse caso, referem-se a determinadas especificidades da metodologia utilizada, pois a elaboração de uma narrativa exige o desenvolvimento de uma construção identitária e a organização e a ordenação dos acontecimentos de sua vida.

Assim, aos critérios de inclusão, inicialmente estabelecidos, foi acrescida uma entrevista prévia com os possíveis participantes, a qual contava com perguntas acerca de dados pessoais e do histórico da situação de rua e de saúde, a partir da qual seria possível avaliar a possibilidade (ou não) de se construir uma entrevista narrativa. A inclusão desse momento foi importante, considerando-se que o convite à pesquisa restrito aos critérios de inclusão iniciais, ante à possibilidade de que não tivessem acurácia de seleção adequada, poderia gerar certa expectativa e frustração nos participantes e na pesquisadora.

Após essa prévia realizava-se o convite para que o indivíduo participasse da pesquisa. Caso o participante não pudesse ou optasse por não realizar a entrevista no momento seguinte ao convite, era possível agendá-la para outro dia. No entanto, percebeu-se que, sendo um grupo de interesse com características próprias e muito específicas, a estratégia de agendamento não funcionou, pois os participantes não voltavam no dia combinado. Assim, quando a entrevista não era realizada no mesmo dia do convite, aguardava-se o próximo encontro espontâneo no serviço.

Depois que as pessoas que atendiam aos critérios de inclusão eram identificadas, com relativa frequência elas ficavam longos períodos sem acessar o serviço novamente, mesmo tendo concordado em participar da pesquisa. Quando retornavam, contavam o que tinha acontecido na sua vida desde o último contato, e as mais diversas justificativas eram dadas para o afastamento: ter ido temporariamente para outro município; ter internado; ou, até mesmo, ter sido preso.

Esse detalhe foi um grande aprendizado, pois, em experiências anteriores de realização de entrevistas com outros grupos, a marcação de dia e horário para o evento mostrou-se uma estratégia bastante efetiva. No entanto, as pessoas que integrariam essa pesquisa, por viverem em situação de rua, exigiram formas mais flexíveis de aproximação. E a longa inserção no campo foi fundamental para esse aprendizado. Isto porque a busca do indivíduo pelo serviço é determinada pelas suas próprias necessidades, segundo outras lógicas de organização, e não por agendamentos predeterminados, sendo que muitos fatores devem ser considerados: a itinerância, a falta de recursos para o uso de transporte, a desconfiança em relação aos serviços, entre outros. No caso da inclusão dessa população na pesquisa, a flexibilização e a customização de estratégias inicialmente previstas foram fundamentais.

Nesse sentido, entende-se que mudanças simples nos procedimentos, conforme o relatado, podem ser fundamentais para remover determinados obstáculos, contribuindo para a efetiva inclusão de participantes considerados relevantes para a pesquisa. ${ }^{17}$

Outra questão desafiadora foi garantir a adequação de uma estratégia de amostragem, articulando o tamanho da amostra com a viabilidade de sua execução, considerando-se as especificidades do grupo participante. Assim, buscou-se uma amostra que permitisse alcançar qualidade nas informações coletadas em relação aos seus usos, ao método de pesquisa específico e ao produto de pesquisa pretendido. 
Para esse fim foi utilizado o critério poder da informação. 0 tamanho de uma amostra com poder de informação suficiente depende do objetivo do estudo, da especificidade da amostra, do uso da teoria estabelecida, da qualidade do diálogo e da estratégia de análise. O poder da informação indica que, quanto mais informações a amostra possuir, e forem relevantes para o estudo real, menor será a quantidade de participantes. ${ }^{17}$

À medida que as entrevistas eram realizadas e transcritas, foram sendo analisadas de modo preliminar, observando-se o seu conteúdo em relação a alguns eixos temáticos: a concepção de cuidado, a interpretação da doença, e os ITs. Isso permitiu que o conjunto de oito entrevistas fosse considerado suficiente, pois a perspectiva metodológica visava aprofundar a forma com que as pessoas em situação de rua com transtornos mentais interpretavam e davam sentido a essa condição, considerando a sua história de vida, e de que forma buscavam o seu cuidado.

Destaca-se que realizar esse número de entrevistas narrativas foi um desafio, exigindo longa inserção no campo. Mesmo sendo um serviço voltado para pessoas em situação de rua, não existe um olhar, um foco, para as questões relacionadas às suas necessidades de cuidados em saúde mental.

\section{Realização da entrevista narrativa}

A obtenção das narrativas iniciou seis meses após a entrada no campo, no período de julho a outubro de 2019 . Das oito entrevistas realizadas, cinco atenderam aos critérios metodológicos de uma entrevista narrativa e foram submetidas à análise. As três que não foram analisadas foram excluídas por limites relacionados à compreensão do seu conteúdo, devido à linguagem confusa e desorganizada do participante ou pela dificuldade dele em relatar a sua história e em estabelecer um encadeamento dos fatos.

Para a realização da entrevista foram seguidas as seguintes etapas: ${ }^{8}$ contato e negociação, explicando o modus operandi ao informante; história principal ou narração central; fase de questionamentos e das recomendações ${ }^{18}$ sobre as regras de realização das entrevistas narrativas.

A fase de contato e negociação ocorreu a partir do convite aos participantes. Naquele momento foram explicitados os objetivos da pesquisa, ressaltando-se a importância das experiências de vida do possível participante para o projeto. Na maioria dos casos, os possíveis participantes reagiram à proposta da pesquisadora de maneira positiva. Aos que aceitaram participar, explicou-se o modus operandi da entrevista, a partir da leitura do Termo de Consentimento Livre e Esclarecido.

Ao realizar a solicitação da narrativa, além da proposta do relato, foram fornecidas as seguintes instruções sobre a entrevista narrativa: "Estou interessada na história de vida de pessoas que moram ou tenham experiência na rua e também tenham transtornos mentais. Gostaria que você contasse sobre sua história de vida, não apenas sobre a sua doença, mas também a sua história e o que mais você achar importante falar. Você pode relatar todas as experiências que vierem à memória, e utilizar o tempo que for necessário. No início, eu não vou fazer nenhuma interrupção, vou apenas tomar notas, para mais tarde retomar alguns temas. Caso não consigamos finalizar hoje, podemos marcar uma segunda entrevista".

A partir disso, iniciou-se a fase de narração central. E à medida que o objeto da narrativa fosse a história de vida do informante, e transcorresse compreensivelmente, a narrativa não era interrompida pela pesquisadora, visando ao maior detalhamento e respeitando o sistema de relevância do entrevistado. ${ }^{8}$

É importante ressaltar que os pesquisadores que usam técnicas de entrevista narrativa não estabelecem uma agenda fixa, mas tendem a deixar o entrevistado controlar a direção, 0 conteúdo e o ritmo da entrevista. ${ }^{19}$

Durante as entrevistas, alguns participantes desenvolveram narrativas mais longas e contínuas, enquanto outros cessavam a narração rapidamente. Nesses casos, buscando estimular a narrativa sem adentrar, ainda, nas fases de questionamento, foram utilizados estímulos como: "e o que aconteceu em seguida?". Durante essa fase foram realizadas anotações, visando ao desenvolvimento das questões e seu aprofundamento na etapa posterior, no intuito de esclarecer inconsistências e preencher lacunas. Em geral, anotaram-se palavras-chave, sempre tomando como referência o dizer do entrevistado e sua sequência de relevância. O final da fase de narração central ocorreu após a indicação de uma coda narrativa (uma clara indicação de término), conforme consta nos exemplos a seguir.

\section{E até hoje tô aqui. Toda a minha história. (Luis)}

Foi um prazer contar a minha história. (Geni)

Só isso que eu tenho pra falar. Se tu quiser perguntar mais alguma coisa. (Sarita)

Feitos os "fechamentos", iniciou-se a fase de questionamentos, na qual foi explorado o potencial narrativo para sub-histórias adicionais, principalmente a partir das anotações realizadas. Respeitou-se a sequência das anotações, tomando novamente como referência a estruturação temática e de relevância desenvolvida pelo participante. Desse modo, buscou-se desvelar o que foi cortado ou resumido na etapa anterior, visando à verificação e ao aprofundamento dos eventos abordados.

Ressalta-se a importância de essas perguntas apresentarem características narrativas, evitando-se questões que possam ter como respostas justificativas ou argumentações, pois o que se busca é a obtenção de mais narrativas. ${ }^{18}$ Além disso, em caso de discrepâncias ou informações imprecisas, ao formular as questões deve-se restaurar o status quo ante o processo narrativo, isto é, retornar da passagem de texto imprecisa ou discrepante na linha principal da história até o último ponto textual de clareza. ${ }^{8}$

Essa etapa, como previsto, foi bastante heterogênea entre os participantes. Alguns, mesmo com perguntas com potencial narrativo, ainda desenvolveram histórias com poucos detalhes e, nesses casos, foi preciso fazer mais questionamentos, buscando explorar a narração. Insistiu-se com questionamentos em pontos de imprecisão e discrepâncias, porém, tendo em mente que eram momentos que apontavam para experiências biográficas difíceis de desvanecer, de racionalizar ou de legitimar, e que não manifestálas fazia parte do sistema de defesa pessoal do informante. 
Conta-me mais um pouco sobre a tua infância, até os teus 17 anos. Antes de sair da casa da mãe. Como era a tua vida?

\section{E aí depois da infância, o que foi acontecendo? \\ Consegues falar um pouco mais dessas dificuldades?}

Ainda nessa fase surgiram questionamentos descritivos e argumentativos, resultando no incentivo à descrição abstrata de situações, de percursos e de contextos sistemáticos. Nesse processo narrativo, foram destacados os contextos maiores do curso de vida, marcados e anotados em posições de relevância especial. Também surgiram os entroncamentos das experiências resultantes de acontecimentos e de desenvolvimentos que não estavam totalmente conscientes para o próprio narrador. ${ }^{8}$

Feitas essas ponderações, acrescenta-se que, quando as questões baseadas nas anotações se encerravam, eram feitas perguntas relacionadas ao campo temático da pesquisa, caso não houvessem sido mencionadas até aquele momento. A pergunta inicial foi: "Como você busca ajuda para seus problemas de saúde?"; a partir dela, outras poderiam surgir:

\section{O que ajuda a melhorar os teus problemas? \\ E o que ou quem te ajudava nisso?}

Dada a conclusão da entrevista narrativa, atentava-se para o cuidado de nunca terminá-la após a narração de uma época traumática ou de fase difícil da vida. Em alguns casos, quando a finalização espontânea ocorreu com a narrativa de fatos ou experiências negativas, incluiu-se a seguinte questão: "Qual foi a sua experiência mais alegre?". Ainda, ao final, foi oportunizado a todos que se manifestassem com o seguinte questionamento: "Há mais alguma coisa que você gostaria de me contar hoje?". Assim, foram finalizadas as entrevistas.

Para que fosse possível manter a mente aberta às subjetividades de cada nova narrativa, no sentido de que não sofresse interferência de pressupostos e julgamentos da pesquisadora, foi necessário um exercício de distanciamento de cada entrevista anterior. Para isso, buscou-se a suspensão das experiências pessoais e teóricas, a fim de de que o conteúdo das entrevistas fosse originalmente do participante.

\section{Análise do material empírico}

Para análise das entrevistas, a fim de interpretar as experiências narradas pelos participantes, foi utilizado o método proposto por Fritz Schütze ${ }^{8}$, composto por seis passos: 1) análise formal do texto;2) descrição estrutural do conteúdo;3) abstração analítica; 4) análise do conhecimento; 5) comparação contrastiva; 6) elaboração de um modelo teórico.

Ressalta-se que a leitura na íntegra das transcrições das entrevistas foi realizada previamente, no início da primeira etapa, para que houvesse melhor compreensão geral do material a ser analisado.

O primeiro passo, a análise formal do texto, consistiu, inicialmente, em eliminar todas as passagens não narrativas, ou seja, as descritivas e as argumentativas, para, em seguida, ordenar o texto narrativo "puro", identificando-se as trajetórias de vida, marcando-se o início e finalização de cada uma, conforme o exemplo a seguir.

[1 - início] Eu, que eu me lembre, eu morava com a minha vó, a minha vó por parte de pai, na Mário Quintana. Aí depois teve um debate com a minha mãe, referente a nossa guarda. Daí passou por Conselho Tutelar, pro juiz da Primeira Vara da Infância e da Juventude, deu a guarda minha e da minha irmã pra nossa vó. Daí a minha mãe aproveitou que tava só nós três sozinho e pegou e fugiu com nós. Levou nós pra Bom Jesus. Lá ela pegou e deixou nós lá, numa casa, e se sumiu. Aí nós tava até com o Ryan, um bebezinho que ela levou também, que é nosso irmão. Aí a mulher que morava lá pegou e nos acolheu. Aí a minha vó foi lá com o Conselho, e pegou eu e a minha irmã, e o Ryan ficou lá. Aí ele foi adotado por aquela família. E eu e minha irmã pegamos e fomos morar com a nossa vó. Aí teve um dia que ela tava com um companheiro e ele começou a beber. Os dois, né? $E$ do nada ele começava a discutir. Aí ele pegou o dinheiro dela, saiu e ela foi atrás dele. Aí ele pegou e empurrou ela na faixa e o carro pegou e atropelou ela. Daí ela faleceu. Ai nosso vô pegou e entregou nós pro Conselho. Eu e minha irmã nós ia ser separado, adotado por família diferente. Aí nosso vô falou que não era bom separar os irmão, daínós fomo pro abrigo, pra Casa de Acolhimento. Aí de lá ficamo um ano, depois nós fomos pra uma instituição, uma casa lar, Social de Fé. Lá eu fiquei até os 18. [1 - finalização]

No segundo passo, descrição estrutural do conteúdo, analisou-se detalhadamente cada segmento da narração, já formalmente delimitado na etapa anterior. Trata-se da etapa mais minuciosa do processo de análise, na qual se deve verificar não só o que está sendo narrado, mas também como a narrativa está sendo construída. Portanto, as dimensões descritivas e argumentativas, excluídas na etapa anterior, foram consideradas nesse momento da análise. A partir disso, buscou-se identificar as diferentes estruturas processuais no curso da vida, empregandose os seguintes marcadores formais: ponto dramático; situação culminante; construção de fundo; passagem argumentativa e passagem explicativa, a seguir descritos.

a) Ponto dramático - evento que gerou transformações na trajetória do participante:

Ela me vendeu pra essa boate. Eu tinha treze anos. (Geni) Só que o Júlio nesse tempo, ele começou a ficar doente. (Geni)

b) Situação culminante - repercussão decorrente do ponto dramático:

\section{Acabei saindo da casa da minha mãe. (Luis)}

Depois eu fiquei na "vida louca". Comecei a ficar na rua, morar na rua. (Sarita) 
c) Construção de fundo - contexto em que a passagem narrativa está situada:

Meu pai era motorista de ônibus e a minha mãe era dona de casa. Meu pai era minha mãe e meu pai. Minha mãe vivia no hospital, ela tinha problema de nervos e o meu pai comprava as coisas pra dentro de casa e a minha mãe tocava tudo dentro do poço. (Sarita)

d) Passagem argumentativa - reflexões e justificativas atuais sobre eventos do passado:

Porque eu não tinha a minha mãe para me dar esse auxílio, entendeu? E eu tinha vergonha de pedir pro meu pai porque eu via que ele era muito trabalhador. (Geni)

A minha infância foi boa apesar de tudo. Foi boa apesar da ausência da minha mãe. (Rita)

e) Passagem explicativa - informações que descrevem e caracterizam elementos da narrativa:

Quando a pessoa tem derrame, a pessoa começa a passar mal. Tem uma parte do corpo que começa a ficar mais difícil de movimentar. (Geni)

Coleção da Marta Rocha é uns perfumezinho, assim, pequenininho, que tem nas mansão. É caro. Cada perfume agora custa cinquenta reais, setenta. Então em cada caixinha acho que vem sete...seis ou sete perfume.(Geni)
A etapa seguinte, abstração analítica, teve o objetivo de reconstruir a biografia como um todo, ordenar os acontecimentos e as trajetórias, verificar as expressões estruturais abstratas de cada período da vida, colocando-as em relação sistemática umas com as outras. Para isso, elaborou-se o Quadro 1, composto da construção de fundo, do ponto dramático e da situação culminante de cada trajetória .

O quarto passo, a análise do conhecimento, permitiu explicitar os aportes teóricos argumentativos do participante sobre sua história de vida, sua identidade e suas trajetórias. Fezse a análise tanto a partir das passagens narrativas quanto das argumentativas e descritivas, pois esses aportes são resultado da interpretação que o participante faz sobre si mesmo e sobre os acontecimentos e experiências presentes em suas trajetórias, representando suas opiniões, conceitos, teorias gerais e reflexões.

Nesse passo da análise, buscou-se elementos da narrativa que permitissem a construção do IT de cada participante, considerando-se suas concepções de cuidado, como e onde buscava esse cuidado, os atores envolvidos na busca e as interpretações da doença que permeavam essas escolhas.

A partir desses eixos fez-se a comparação contrastiva, que consistiu no agrupamento e na análise do conjunto das entrevistas, buscando-se semelhanças e diferenças entre os casos, individualmente; fazendo uma comparação contrastiva de diferentes textos de entrevistas ao analisar situações paralelas às encontradas na análise da primeira entrevista. Assim, obteve-se um grau maior de abstração em relação às análises realizadas, à medida que o caso deixou de ser tratado como individual, e as condições que estavam por detrás da particularidade de cada um

Quadro 1. Abstração analítica: reconstrução da história de vida.

\begin{tabular}{|c|c|c|c|}
\hline Trajetória 1 & Trajetória 2 & Trajetória 3 & Trajetória 4 \\
\hline Construção de fundo & Construção de fundo & Construção de fundo & Construção de fundo \\
\hline $\begin{array}{l}\text { Infância, morando com a } \\
\text { mãe e os irmãos em Recife. } \\
\text { Frequentava a escola e a } \\
\text { igreja e ficava bastante } \\
\text { tempo dentro de casa. Tem } \\
\text { as primeiras experiências } \\
\text { com audição de vozes. }\end{array}$ & $\begin{array}{l}\text { Depois que sai da casa da } \\
\text { mãe, inicia uma vida de } \\
\text { viagens por diversas cidades } \\
\text { do Nordeste, fazendo } \\
\text { pequenos trabalhos. Retorna } \\
\text { algumas vezes para a casa da } \\
\text { mãe. Tenta suicídio. Troca de } \\
\text { religião, passando a ser do } \\
\text { Candomblé. }\end{array}$ & $\begin{array}{l}\text { Foi tentar a vida em São } \\
\text { Paulo. Lá relata dificuldades, } \\
\text { tem experiência na } \\
\text { cracolândia, em situação } \\
\text { de rua. Voltou para Recife, } \\
\text { conseguiu emprego, alugou } \\
\text { quarto e esteve em um } \\
\text { relacionamento. }\end{array}$ & $\begin{array}{l}\text { Trajetória atual. Quando } \\
\text { chegou trabalhava, não } \\
\text { tinha mulher. Perdeu tudo } \\
\text { quando começou usar outra } \\
\text { droga e quer recuperar. } \\
\text { Corta os braços e ouve a } \\
\text { voz de Exu, seu guia. }\end{array}$ \\
\hline Ponto dramático & Ponto dramático & Ponto dramático & \\
\hline $\begin{array}{c}\text { Começa a beber e usar } \\
\text { drogas aos } 17 \text { anos }\end{array}$ & $\begin{array}{c}\text { Tenta suicídio e é impedido } \\
\text { pela polícia }\end{array}$ & $\begin{array}{l}\text { Foi desligado do albergue em } \\
\text { São Paulo por usar drogas no } \\
\text { mesmo }\end{array}$ & \\
\hline Situação culminante & Situação culminante & Situação culminante & \\
\hline Sai da casa da mãe & Volta para a casa da mãe & Volta para a casa da mãe & \\
\hline
\end{tabular}

Fonte: Dados da pesquisa 
Quadro 2. Comparação contrastiva.

\begin{tabular}{|c|c|c|c|c|}
\hline SARITA & Luís & GENI & RITA & JOÃO \\
\hline Família & Igreja Evangélica & Família & Família & Conselho Tutelar \\
\hline $\begin{array}{c}\text { (tia, pai, mãe) } \\
\text { figuras centrais; } \\
\text { providenciaram } \\
\text { internação em hospital } \\
\text { psiquiátrico; cuidava } \\
\text { da filha }\end{array}$ & $\begin{array}{c}\text { fazendo parte do } \\
\text { sistema cultural da } \\
\text { família, sendo "criado" } \\
\text { na Igreja Evangélica }\end{array}$ & $\begin{array}{l}\text { (pai e vó) cuidado } \\
\text { intrafamiliar, } \\
\text { operacionalizado nas } \\
\text { coisas do cotidiano }\end{array}$ & (avô, pai) & $\begin{array}{c}\text { guarda e recuperação } \\
\text { dele e da irmã para a } \\
\text { casa da avó. Primeira } \\
\text { instituição responsável } \\
\text { após a morte da avó, } \\
\text { que encaminhou ao } \\
\text { abrigo }\end{array}$ \\
\hline \multirow[t]{2}{*}{ Hospitais psiquiátricos } & Trabalho & Boate & Setor profissional & $\begin{array}{l}\text { Abrigo (Casa de } \\
\text { acolhimento) }\end{array}$ \\
\hline & $\begin{array}{l}\text { venda de acarajé e } \\
\text { refrigerante; permitiu } \\
\text { que pudesse fazer as } \\
\text { viagens. }\end{array}$ & $\begin{array}{c}\text { como moradia, } \\
\text { trabalho, acesso a } \\
\text { serviço de saúde, lazer }\end{array}$ & $\begin{array}{l}\text { começou a tomar } \\
\text { remédios }\end{array}$ & \\
\hline $\begin{array}{l}\text { Pessoas da } \\
\text { comunidade }\end{array}$ & Polícia & Médico/ medicação & Sine & Abrigo (Casa Lar) \\
\hline $\begin{array}{c}\text { doando roupas e } \\
\text { alimentos }\end{array}$ & $\begin{array}{l}\text { impediu o suicídio e } \\
\text { o levou para um local } \\
\text { seguro }\end{array}$ & & $\begin{array}{l}\text { local para busca de } \\
\text { emprego e onde } \\
\text { conheceu marido }\end{array}$ & $\begin{array}{c}\text { instituição que o } \\
\text { abrigou por oito anos }\end{array}$ \\
\hline
\end{tabular}

Fonte: Dados da pesquisa

passaram a ser analisadas. No Quadro 2, a seguir, exemplificase a comparação realizada em relação aos ITs.

O último passo foi a construção de um modelo teórico, resultado da comparação das trajetórias individuais, que, após sua exaustiva comparação, estabeleceu semelhanças que permitiram o reconhecimento de trajetórias coletivas.

Assim, tem-se, ao final da análise,

modelos processuais de tipos específicos de cursos de vida, de suas fases, de suas condições e domínios de problemas, ou ainda modelos processuais de fases elementares específicas; módulos gerais de cursos de vida ou das condições constitutivas e da estrutura da formação biográfica como um todo $8: 215$

A análise de narrativas permitiu acessar, em profundidade, o relato das experiências mediante a fala livre dos participantes, com o objetivo de construir os ITs de pessoas em situação de rua com transtornos mentais, e os sentidos e significados da doença e do cuidado que podem ter determinado as escolhas em suas trajetórias de vida.

\section{CONCLUSÕES}

A entrevista narrativa, como ferramenta metodológica para a construção de itinerários terapêuticos de pessoas em situação de rua com transtornos mentais, além de ser uma técnica de produção de dados, traz uma perspectiva que possibilita "fazerse ouvir" em histórias que são, frequentemente, negligenciadas. Esse método tem como foco central a construção de sentido(s) por parte de quem vivencia determinada realidade, considerandose ações, decisões e escolhas mobilizadas e que conferem os contornos a sua biografia.

A entrevista narrativa também permite a reconstrução desses sentidos, possibilitando novos olhares e insights em relação à própria experiência de quem relata, considerando-se que, às vezes, devido a certas interpretações cristalizadas, ocorrem bloqueios na trajetória biográfica. No caminho da busca pela visibilidade desse grupo, que precisa de um olhar singularizado, a entrevista narrativa possibilita tematizar as situações, com sensibilidade, ao propor um método dialógico e compreensivo. Além disso, a análise das biografias e trajetórias de pessoas em situação de rua e com transtornos mentais pode impulsionar o movimento de (re)pensar o cuidado em saúde mental, considerando-se aspectos que possam se configurar potencializadores do lugar da atenção psicossocial na inclusão e acesso desse grupo.

Os limites encontrados na utilização da entrevista narrativa com esse grupo dizem respeito a algumas especificidades: os 
entrevistados eram pessoas com histórias predominantemente relacionadas a carências, perdas e traumas, e a construção de narrativas envolvia retomar essas situações. Nessa direção, perceberam-se momentos em que não cabia o aprofundamento de algumas dessas narrativas, as quais, ao menos naquele momento, não teriam relevância para o objetivo desta pesquisa. Isso exigiu sensibilidade da pesquisadora para poder diferenciar em que momentos cabia ou não estimular o relato. Outra questão limitadora foi a itinerância do grupo e a dificuldade de aproximação e de estabelecimento de uma relação de confiança. Para minimizar essa limitação, recomenda-se prever uma inserção contínua e longa no campo em futuros estudos.

Apresenta-se também como limite a pouca experiência que se possuía na utilização da entrevista narrativa. Apesar de ter o domínio da investigação qualitativa e de entrevistas semiestruturadas, percebeu-se que entender como as pessoas em situação de rua com transtornos mentais buscavam o seu cuidado exigiria uma aproximação com o modo com que interpretavam essa experiência e como agiam em relação a ela no contexto de situações específicas da sua vida. Era preciso usar um método de pesquisa que permitisse aos participantes abordarem o tópico e lhes proporcionasse uma maneira para descrever suas experiências pessoais como um fenômeno social complexo; o formato de perguntas e respostas de entrevistas semiestruturadas convencionais não funcionaria.

\section{CONTRIBUIÇÕES DOS AUTORES}

Desenho do estudo e do relato de experiência. Letícia Passos Pereira. Christine Wetzel.

Aquisição de dados. Letícia Passos Pereira.

Análise de dados. Letícia Passos Pereira. Christine Wetzel. Evelyn Klein.

Interpretação dos resultados. Letícia Passos Pereira. Christine Wetzel. Agnes Olschowsky. Bárbara Maix Moraes. Evelyn Klein.

Redação e revisão crítica do manuscrito. Letícia Passos Pereira. Christine Wetzel. Fabiane Machado Pavani. Agnes Olschowsky. Bárbara Maix Moraes. Evelyn Klein.

Aprovação da versão final do artigo. Letícia Passos Pereira. Christine Wetzel. Fabiane Machado Pavani. Agnes Olschowsky. Bárbara Maix Moraes. Evelyn Klein.

Responsabilidade por todos os aspectos do conteúdo e a integridade do artigo publicado. Letícia Passos Pereira. Christine Wetzel. Fabiane Machado Pavani. Agnes Olschowsky. Bárbara Maix Moraes. Evelyn Klein.

\section{EDITOR ASSOCIADO}

\section{Cristina Rosa Baixinho}

\section{REFERÊNCIAS}

1. Pimenta MM. Pessoas em situação de rua em Porto Alegre: processos de estigmatização e invisibilidade social. Civitas. 2019;19(1):82-104. http://dx.doi.org/10.15448/1984-7289.2019.1.30905.
2. Nonato DM, Raiol RWG. Pessoas em situação de rua e violência: entrelaçados em nome da suposta garantia de segurança pública. Rev Direito Debate. 2018;27(49):90-116. http://dx.doi.org/10.21527/21766622.2018.49.90-116.

3. Chrystal JG, Glover DL, Young AS, Whelan F, Austin EL, Johnson NK et al. Experience of primary care among homeless individuals with mental health conditions. PLoS One. 2015;10(2):e0117395. http://dx.doi org/10.1371/journal.pone.0117395. PMid:25659142.

4. Ayres JRCM. Cuidado: trabalho, interação e saber nas práticas de saúde. Rev baiana enferm. 2017;31(1):1-4. http://dx.doi.org/10.18471/ rbe.v31i1.21847.

5. Alves PC. Itinerário terapêutico, cuidados à saúde e a experiência de adoecimento. In: Gerhardt TE, Pinheiro R, Ruiz ENF, Silva Junior AG, organizadores. Itinerários terapêuticos: integralidade no cuidado, avaliação e formação em saúde. Rio de Janeiro (RJ): CEPESC/IMSUERJ/ABRASCO; 2016. p. 125-46

6. Gerhardt TE, Riquinho DL. Sobre itinerários terapêuticos em contextos de iniquidade social: desafios e perspectivas contemporâneas. In: Jorge MSB, Pinheiro R, Mota CS, Rocha AARM, organizadores. Contextos, parcerias e itinerários na produção do cuidado integral: diversidade $e$ interseções. Rio de Janeiro (RJ): CEPESC/ABRASCO; 2015. p. 364.

7. Pereira LP, Wetzel C, Pavani FM, Moraes BM, Olschowsky A, Kirch I. A entrevista narrativa na construção de itinerários terapêuticos de pessoas em situação de rua com transtornos mentais graves. Resumos dos trabalhos apresentados no 80 Congresso Ibero-Americano em Investigação Qualitativa em Saúde; 2019 jul. 16-19; Lisboa, Portugal. Lisboa: CIAIQ; 2019. p. 185-90.

8. Schütze F. Pesquisa biográfica e entrevista narrativa. In: Weller W, Pfaff $\mathrm{N}$, organizadores. Metodologias da pesquisa qualitativa em educação: teoria e prática. Petrópolis (RJ):Vozes; 2010. p. 211-22.

9. Jovchelovich S, Bauer MW. Entrevista narrativa. In: Bauer MW, Gaskell G. Pesquisa qualitativa com texto, imagem e som: um manual prático. 13ª ed. Petrópolis (RJ): Vozes; 2017. p. 90-113.

10. Artioli $G$, Cosentino $C$, Taffurelli $C$, Ferri P, Foà $C$. The narrative interview for the assessment of the assisted person: Structure, method and data analysis. Acta Biomed. 2019;90(2):7-16. https://doi.org/10.23750/abm. v90i6-S.8640.

11. Mueller RA. Episodic narrative interview: capturing stories of experience with a methods fusion. Int J Qual Methods. 2019;18:1-11. http://dx.doi. org/10.1177/1609406919866044.

12. Silva DGV, Trentini M. Narrativas como a técnica de pesquisa em enfermagem. Rev latinoam enferm. 2002;10(3):423-32. http://dx.doi. org/10.1590/S0104-11692002000300017.

13. Bellato R, Araújo LFS, Maruyama SAT, Ribeiro AL. História de vida como abordagem privilegiada para compor itinerários terapêuticos. In: Gerhardt TE, Pinheiro R, Ruiz ENF, Silva Junior AG, organizadores. Itinerários terapêuticos: integralidade no cuidado, avaliação e formação em saúde. Rio de Janeiro: CEPESC/ABRASCO; 2016. p. 203-21.

14. Creswell JW. Investigação qualitativa e projeto de pesquisa: escolhendo entre cinco abordagens. $3^{\mathrm{a}}$ ed. Porto Alegre (RS): Penso; 2014. p. 342.

15. Moreira DJ, Bosi MLM, Soares CA. Uso de narrativas na compreensão dos itinerários terapêuticos de usuários em sofrimento psíquico. In: Gerhardt TE, Pinheiro R, Ruiz ENF, Silva Junior AG, organizadores. Itinerários terapêuticos: integralidade no cuidado, avaliação e formação em saúde. Rio de Janeiro (RJ): CEPESC; 2016. p. 223-36.

16. Cardano M. Manual de pesquisa qualitativa: a contribuição da teoria da argumentação. Petrópolis (RJ): Editora Vozes; 2017. p. 376.

17. Malterud K, Siersma VD, Guassora AD. Sample size in qualitative interview studies: guided by information power. Qual Health Res. 2016;26(13):175360. http://dx.doi.org/10.1177/1049732315617444. PMid:26613970.

18. Rosenthal G. Pesquisa social interpretativa: uma introdução. $5^{\mathrm{a}}$ ed Porto Alegre (RS): Edipucrs; 2014. p. 576.

19. Anderson C, Kirkpatrick S. Narrative interviewing. Int J Clin Pharm 2016;38(3):631-4. http://dx.doi.org/10.1007/s11096-015-0222-0. PMid:26613739. 